\title{
Editorial
}

\section{After the Pandemic}

\author{
Indranil Chakravorty PhD, Abhay \\ Chopada FRCS \& Vipin Zamvar FRCS \\ (CTh)
}

\section{The Impact of COVID-19}

Cite as: Chakravorty, I., Chopada, A., Zamvar, V. Editorial: After the Pandemic- The impact of COVID-19. The Physician 2020 vol6; issue2 Epub 12.09.2020 DOI: 10.38192/1.6.2.25

\begin{tabular}{ll}
\multicolumn{2}{l}{ Article Information } \\
\hline Submitted & 12.09 .2020 \\
Epub & 12.09 .2020 \\
Open access & Creative Commons \\
Licence CC-BY-ND-4.0
\end{tabular}

\section{Background}

Some parts of the world including the UK, are emerging from the storm of COVID-19. What is presumed to have originated from a market in Wuhan, China back in November 2019, has swiftly spread its devastation across the globe.1 At the last count in September 2020, there are nearly 900,000 deaths and over 27 million cases.2 COVID-19 has not only wreaked havoc on lives, health, and livelihoods of humanity but also touched every aspect of civilization, and disrupted every equilibrium that modern society has learned to expect.

Not all such disruption has been destructive, akin to the changes experienced after such catastrophic events as the World Wars, there has been a surge of innovation and progress in many ways. The much-maligned lockdown policies enacted by several governments variably across the world, while brutally separating people from their families and loved ones across continents, has also brought us together. There has never been so much collaboration of scientific, economic, social, and political thinkers across the world. Science and technology, especially digital access has become ubiquitous in every aspect of society. Education and enterprise have been delivered digitally across the internet in almost every country in the world, whether rich or small.

There have been many tragedies, industries such as travel, airlines, and hospitality have folded. Manufacturing that depends on the swift movement of goods or components across the world has halted. Household names have been lost. Even the most 'healthy and resilient' economies have shrunk by almost

a third. The effects on employment, therefore livelihoods and lives are huge.

Health is intricately linked to and interdependent on the wealth of economies. So the impact on health even after the COVID-19 pandemic abates (although there are no signs of that yet) will be felt for generations. Yet our survival depends on the indomitable nature of the human spirit. The articles in this issue of The Physician will explore the long view of the impact on health, consider the shoots of recovery, and the nature of innovations and developments which will make the world better equipped to deal with such maladies in the future. As healthcare professionals, we have a duty of care to all our patients and peers.

\section{Impact on Health}

There is growing evidence from follow up of patients that the SARS-CoV-2 virus which causes COVID-19 is not restricted in its influence on the pulmonary system but causes a longlasting impact on multiple systems of the individual. We now know that the virus affects individuals variably dependent on a variety of host factors. The multi-system manifestation of a COVID-19 infection 3,4 is caused by a combination of specific host defense responses with associated inflammatory activity and (micro) vascular involvement with distinct coagulopathy and thromboembolic complications. The hyper-inflammatory tissue response in a proportion of patients leads to multiple organ dysfunction affecting the lungs, heart, kidneys, nerves, muscles, gastrointestinal tract, and brain. In the patients most severely affected, a cytokine "storm" occurs, characterized by very high levels of pro-inflammatory cytokines and Tumour Necrosis Factor (TNF)- $\alpha$, interleukins, granulocyte-colony stimulating factor, and several chemokines. 5,6 These patients 
are those at the highest risk of multi-system failure and significant mortality. Males and those with pre-existing hypertension or coronary disease are at higher risk of severe disease, consistent with known correlates of angiotensinconverting enzyme type 2 gene (ACE-2) expression. $\underline{ }$

Considering the cardiovascular system, cardiac enzyme release can be observed even in the early stages, suggesting myocardial inflammation and damage. $\underline{8-10}$ Acute kidney injury (AKI) and often renal failure are recognized in COVID-19 patients. Although proteinuria, haematuria, and AKI often resolved in such patients, renal complications in COVID-19 are associated with high mortality.11 Gut and liver dysfunction, manifest by deranged tests of liver function and slow tolerance of enteral feeding, are well recognized. Some patients also report diarrhoea, vomiting, and abdominal pain. SARS-CoV-2 RNA is identified in stool specimens of infected patients, and its viral receptor ACE-2 is found to be highly expressed in gastrointestinal epithelial cells. 12

Neurologic abnormalities are documented in up to $50 \%$ of the most severely ill patients, including impaired consciousness, acute cerebrovascular events, and muscle dysfunction, 13 manifested as headache, nausea, and vomiting. The SARS-CoV has been reported in the brains of both patients and experimental animals, where the brainstem is heavily infected. Furthermore, some coronaviruses have been demonstrated able to spread via a synapse-connected route to the medullary cardiorespiratory center from the mechanoreceptors and chemoreceptors in the lung and lower respiratory airways. ${ }_{14}$ Children who are expected to have a low prevalence of disease and manifest only the mildest of symptoms, also are at risk of a multi-system manifestation.15

In addition to being male, of greater age and deprivation, diabetes, severe asthma, and various other medical conditions, ethnicity was also found to be a significant determinant of death due to COVID-19. Compared with people of white ethnicity, Black and South Asian people were at higher risk, even after adjustment for other factors. 16

Once the acute phase is over, there is the issue with a postviral syndrome which can manifest in long term fatigue, pulmonary, cardiovascular, and renal dysfunction. Postintensive care syndrome (PICS) patients can have some combination of physical impairment, cognitive impairment, and psychiatric impairment. In the absence of an established consensus, Long-COVID is a term coined and defined and includes, (1) post-acute COVID-19 extending beyond three weeks from the onset of first symptoms and (2) chronic COVID-19 as extending beyond 12 weeks. Since many people were not tested, and that false-negative tests are common, hence a positive diagnosis is not considered essential for consideration in such cases. 17

Around $10 \%$ of patients who have tested positive for SARSCoV-2 virus remain unwell beyond three weeks, and a smaller proportion for months. A study found that only $65 \%$ of people had returned to their previous level of health 1421 days after a positive test.18 19 Recovery after any severe debilitating illness may be prolonged. Survivors of COVID-19 acute respiratory distress syndrome are at risk of long term impairment of lung function. Serious interstitial lung disease seems to be rare in patients who are not hypoxic, though data on long term outcomes are not yet available. Those who have had significant respiratory illness may benefit from pulmonary rehabilitation, which includes, exercise training and behavioural modification designed to improve the physical and psychological condition. In the context of COVID-19, rehabilitation can be delivered by virtual models. There is much debate and controversy about the role of graded exercise in chronic fatigue generally 20 and in COVID19 in particular. 31

Perhaps $20 \%$ of patients admitted with COVID-19 have clinically significant cardiac involvement, occult involvement maybe even commoner. Cardiopulmonary complications include myocarditis, pericarditis, myocardial infarction, dysrhythmias, and pulmonary embolus may present several weeks after acute COVID-19. They are commoner in patients with pre-existing cardiovascular disease, 22 but they have also been described in young, previously active patients. 22 In this issue, we present the prevalence data from patients admitted with COVID-19 to a London hospital and the message that up to half of the patients may have persistent cardiac dysfunction needing monitoring. Intense cardiovascular exercise must be avoided for three months in all patients after myocarditis or pericarditis; athletes are advised to take three to six months of complete rest from cardiovascular training followed by specialist follow-up, with the return to sport guided by functional status, biomarkers, absence of dysrhythmias, and evidence of normal left ventricular systolic function

\section{Thromboembolism}

COVID-19 is an inflammatory and hypercoagulable state, with an increased risk of thromboembolic events. Many hospitalised patients receive prophylactic anticoagulation. We have reported a case report of a COVID-19 patient returning to the hospital with a major pulmonary embolism. 23 Recommendations for anticoagulation after discharge vary, but higher-risk patients are typically discharged from the hospital with 10 days of extended thromboprophylaxis. It is not known how long patients remain hypercoagulable following acute COVID-19. The case for thrombolysis or management of patients with sub-massive PE remains unclear, as is described from a large case series reported in this issue. 24

COVID-19 tends to affect older patients more severely. 25 Those who survive are at high risk of muscle wasting, malnutrition, depression, and delirium. Physical symptoms add to the psychosocial impact of disrupted access to health care, personal routines, social interactions. 
Most studies report negative psychological effects including post-traumatic stress symptoms, confusion, and anger. Stressors included longer quarantine duration, infection fears, frustration, boredom, inadequate supplies, inadequate information, financial loss, and stigma. Some have suggested long-lasting effects. $\underline{26}$ Most studies on COVID-19 and mental health have emphasised individual reactions to the pandemic such as anxiety, stress, and conditions related to broken routines, loneliness, and social isolation in uninfected individuals; the World Health Organisation has issued guidance on these.27 Added to the fear of contracting the virus in a pandemic such as COVID-19 are the significant changes to daily lives as movement is restricted, people are faced with new realities of working from home, temporary unemployment, home-schooling of children, and lack of physical contact with others. Both for health workers and patients' wellbeing, mindfulness, social connection, self-care (including diet and hydration) and peer support can mitigate some of the impacts. 28

This pandemic has exposed many inequalities in society. COVID-19 is more common and has a worse prognosis in the acute phase in people who are poor, elderly, and from certain minority ethnic groups (notably black, south Asian, and Jewish.29 In a survey with over 1200 responses, the majority (94\%) from BAME backgrounds, a quarter of respondents reported inadequate personal protective equipment, $2 / 3$ could not comply with social distancing and a third reported being reprimanded in relation to PPE, or avoidance of risk. 30 It is imperative that employers consolidate risk reduction measures and foster a culture of safety to encourage employees to voice any safety concerns. It is too early to say whether these sociodemographic patterns persist in postacute COVID-19. Some have experienced family bereavements as well as job losses and consequent financial stress and food poverty. The strain on many carers has been high. For an important few, the lockdown has worsened safeguarding concerns such as the risk of a child or intimate partner abuse.

The direct costs of the COVID-19 pandemic associated with illness and mortality are lower than the indirect losses caused by the crisis. 31 A low impact of COVID-19 in terms of case numbers and deaths does not necessarily translate into a low economic impact. Many countries are experiencing a recession, even though COVID-19 has not had a serious effect on them in terms of health. Even minor public health events can severely affect firms in lower-income countries due to their poor socio-economic conditions (vulnerability) and their weak capacity to respond to crises (resilience). Moreover, in a globalised world, many countries are suffering indirect consequences from value chain disruptions and lower international demand for goods due to widespread recession. The growing COVID-19 crisis threatens to disproportionately hit developing countries, not only as a health crisis in the short term but as a devastating social and economic crisis over the months and years to come. 31 Income losses are expected to exceed \$220 billion in developing countries. With an estimated 55 percent of the global population having no access to social protection, these losses will reverberate across societies, impacting education, human rights, and, in the most severe cases, basic food security and nutrition.

Under-resourced hospitals and fragile health systems are likely to be overwhelmed. This may be further exacerbated by a spike in cases, as up to 75 percent of people in the least developed countries lack access to soap and water. Additional social conditions, such as poor urban planning and overpopulation in some cities, weak waste disposal services, and even traffic congestion impeding access to healthcare facilities, may all add to the caseload.32

The June 2020 Global Economic Prospects 33 describes both the immediate and near-term outlook for the impact of the pandemic and the long-term damage it has dealt with prospects for growth. The baseline forecast envisions a 5.2 percent contraction in global GDP in 2020, using market exchange rate weights - the deepest global recession in decades, despite the extraordinary efforts of governments to counter the downturn with fiscal and monetary policy support. Over the longer horizon, the deep recessions triggered by the pandemic are expected to leave lasting scars through lower investment, an erosion of human capital through lost work and schooling, and fragmentation of global trade and supply linkages.

Policies to rebuild both in the short and long-term entail strengthening health services and putting in place targeted stimulus measures to help reignite growth, including support for the private sector and getting money directly to people. During the mitigation period, countries should focus on sustaining economic activity with support for households, firms, and essential services. Global coordination and cooperation-of the measures needed to slow the spread of the pandemic, and of the economic actions needed to alleviate the economic damage, including international support-provide the greatest chance of achieving public health goals and enabling a robust global recovery. $\underline{20}$ The pandemic has also shifted the expectation matrix away from physical consultation towards virtual consultation this will also spare on more integration of technology and enable universal models of care delivery. Integration across various disciplines including data sciences and clinicians along with electronic engineers hopefully bring about a positive change for future health care delivery models.

We certainly look towards the future of optimism and recognise human resilience as the single most important factor, which should allow us to work through this unpredictable and unfortunate phase of having faced a global pandemic and build a better future.

\section{Bibliography}


1. Zhou P, Yang X-L, Wang X-G, et al. A pneumonia outbreak associated with a new coronavirus of probable bat origin. Nature. 2020;579(7798):270-273. doi:10.1038/s41586-0202012-7

2. Coronavirus Update (Live): $27,069,697$ Cases and 883,771 Deaths from COVID-19 Virus Pandemic - Worldometer. Accessed September 6, 2020.

https://www.worldometers.info/coronavirus/

3. Zheng KI, Feng G, Liu W-Y, Targher G, Byrne CD, Zheng M-H. Extra-pulmonary complications of COVID-19: a multi-system disease? J Med Virol. Published online July 10, 2020. doi:10.1002/jmv.26294

4. Covid-19: a complex multisystem clinical syndrome. The BMJ. Published May 1, 2020. Accessed September 6, 2020. https://blogs.bmj.com/bmj/2020/05/01/covid-19-acomplex-multisystem-clinical-syndrome/

5. Hu B, Huang S, Yin L. The cytokine storm and COVID-19. J Med Virol. Published online June 27, 2020. doi:10.1002/jmv.26232

6. Mehta P, McAuley DF, Brown M, Sanchez E, Tattersall RS, Manson JJ. COVID-19: consider cytokine storm syndromes and immunosuppression. The Lancet. 2020;395(10229):1033-1034. doi:10.1016/S01406736(20)30628-0

7. Zhou F, Yu T, Du R, et al. Clinical course and risk factors for mortality of adult inpatients with COVID-19 in Wuhan, China: a retrospective cohort study. The Lancet. 2020;395(10229):1054-1062. doi:10.1016/S01406736(20)30566-3

8. Szekely Yishay, Lichter Yael, Taieb Philippe, et al. Spectrum of Cardiac Manifestations in COVID-19. Circulation. 2020;142(4):342-353. doi:10.1161/CIRCULATIONAHA.120.047971

9. Kang $Y$, Chen T, Mui D, et al. Cardiovascular manifestations and treatment considerations in COVID-19. Heart. 2020;106(15):1132-1141. doi:10.1136/heartjnl-2020-317056

10. Zheng Y-Y, Ma Y-T, Zhang J-Y, Xie X. COVID-19 and the cardiovascular system. Nature Reviews Cardiology. 2020;17(5):259-260. doi:10.1038/s41569-020-0360-5

11. Pei G, Zhang Z, Peng J, et al. Renal Involvement and Early Prognosis in Patients with COVID-19 Pneumonia. J Am Soc Nephrol. 2020;31(6):1157-1165. doi:10.1681/ASN.2020030276

12. Wong SH, Lui RN, Sung JJ. Covid-19 and the digestive system. J Gastroenterol Hepatol. 2020;35(5):744-748. doi:10.1111/jgh.15047

13. Mao L, Jin H, Wang M, et al. Neurologic Manifestations of Hospitalized Patients With Coronavirus Disease 2019 in Wuhan, China. JAMA Neurol. Published online April 10, 2020. doi:10.1001/jamaneurol.2020.1127

14. Li Y-C, Bai W-Z, Hashikawa T. The neuroinvasive potential of SARS-CoV2 may play a role in the respiratory failure of COVID-19 patients. Journal of Medical Virology.

2020;92(6):552-555. doi:10.1002/jmv.25728

15. BAME children are most at risk of developing Multisystem Inflammatory Syndrome-Temporally Associated with COVID19 | The Physician. Accessed September 6, 2020. https://physicianjnl.net/index.php/phy/article/view/35

16. Collaborative TO, Williamson E, Walker AJ, et al. OpenSAFELY: factors associated with COVID-19-related hospital death in the linked electronic health records of 17 million adult NHS patients. medRxiv. Published online May 7,
2020:2020.05.06.20092999.

doi:10.1101/2020.05.06.20092999

17. Greenhalgh $T$, Knight $M, A^{\prime}$ Court $C$, Buxton $M$, Husain L. Management of post-acute covid-19 in primary care. BMJ. 2020;370. doi:10.1136/bmj.m3026

18. Tenforde MW, Kim SS, Lindsell CJ, et al. Symptom Duration and Risk Factors for Delayed Return to Usual Health Among Outpatients with COVID-19 in a Multistate Health Care Systems Network - United States, March-June 2020. MMWR Morb Mortal Wkly Rep. 2020;69(30):993-998. doi:10.15585/mmwr.mm6930e1

19. Mahase E. Covid-19: What do we know about "long covid"? BMJ. 2020;370. doi:10.1136/bmj.m2815

20. Larun L, Brurberg KG, Odgaard-Jensen J, Price JR. Exercise therapy for chronic fatigue syndrome. Cochrane Database Syst Rev. 2017;4:CD003200. doi:10.1002/14651858.CD003200.pub7

21. statement.pdf. Accessed September 13, 2020. https://www.nice.org.uk/guidance/gidng10091/documents/statement

22. Shi S, Qin M, Shen B, et al. Association of Cardiac Injury With Mortality in Hospitalized Patients With COVID-19 in Wuhan, China. JAMA Cardiol. Published online March 25, 2020. doi:10.1001/jamacardio.2020.0950

23. Rahimzadeh M, Pooprasert P. Pulmonary Embolism in a Post Covid-19 Patient - A Case Report. phy. 2020;6(1). doi:10.38192/1.6.1.8

24. Asthana A, Konar N, Chakravorty I. Mortality from Pulmonary Embolism by Clinical Severity. phy. 2020;6(2). doi:10.38192/1.6.2.17

25. Wang L, He W, Yu X, et al. Coronavirus disease 2019 in elderly patients: Characteristics and prognostic factors based on 4-week follow-up. J Infect. 2020;80(6):639-645. doi:10.1016/j.jinf.2020.03.019

26. Brooks SK, Webster RK, Smith LE, et al. The psychological impact of quarantine and how to reduce it: rapid review of the evidence. The Lancet. 2020;395(10227):912-920. doi:10.1016/S0140-6736(20)30460-8

27. Mental health and COVID-19. Accessed September 6, 2020. https://www.who.int/teams/mental-health-and-substanceuse/covid-19

28. Mistry M. Mindfulness for Healthcare Professionals. Sushruta Journal of Health Policy \& Opinion. 2019;12(1):3333. doi:10.38192/12.1.19

29. Disparities in the risk and outcomes of COVID-19. :92.

30. Daga S, Jafferbhoy S, Menon G, et al. Does Gender or Religion Contribute to the Risk of COVID-19 in Hospital Doctors in the UK? Sushruta Journal of Health Policy \& Opinion. 2020;13(3):1-11. doi:10.38192/13.3.1

31. Coronavirus: the economic impact - 10 July 2020 | UNIDO. Accessed September 13, 2020.

https://www.unido.org/stories/coronavirus-economicimpact-10-july-2020

32. COVID-19: Looming crisis in developing countries threatens to devastate economies and ramp up inequality. UNDP. Accessed September 6, 2020.

https://www.undp.org/content/undp/en/home/newscentre/news/2020/COVID19_Crisis_in_developing_countries threatens devastate_economies.html

33. The Global Economic Outlook During the COVID-19 Pandemic: A Changed World. World Bank. Accessed September 6, 2020.

https://www.worldbank.org/en/news/feature/2020/06/08/t 
he-global-economic-outlook-during-the-covid-19-pandemica-changed-world 
